\title{
Cryotherapy: A Comprehensive Review on Physiology, Advent and Implications in Endodontics
}

\author{
Shreya ${ }^{1}$, Praveen S Samant ${ }^{2}$, Vipul Srivastava $^{3}$, Raju Chauhan $^{4}$, Kishan Agarwal $^{5}$
}

\begin{abstract}
Aim and objective: The aim is to review and discuss the concept of cryotherapy, its physiology, and different clinical implications in endodontics. Background: Cryotherapy alludes to diminishing the tissue temperature for therapeutic purposes. In the field of endodontics, it has started evolving due to its therapeutic properties and its effect on nickel-titanium endodontic instruments in terms of yielding mechanical properties. By using specific keywords, an electronic search of scientific papers was carried out on the entire PubMed database. The last access was august 2020, using combinations of the pre-defined keywords.

Review results: The electronic search yielded 253 papers from the PubMed database; in light of inclusion and exclusion measures which were explicitly foreordained, 13 papers were distinguished as appropriate to the inclusion criteria. Then, a detailed study of all the references of these articles was done manually and electronically. At that point, 25 additional articles were chosen through hand search, the full content of the apparent multitude of articles recovered, and the review was finished. By pooling the separated information from chosen papers, the reviewed information was synthesized.
\end{abstract}

Conclusion: Lately, by demonstrating great promising outcomes with the utilization of cryotherapy, it has demonstrated to have a decent possibility for its utilization as a therapeutic aid in endodontics.

Clinical significance: Cryotherapy is a cost-effective treatment that can be advantageous in numerous clinical circumstances to provide painless and safer endodontic treatment.

Keywords: Cryogenic treatment, Cryotherapy, Nickel-titanium endodontic instruments, Postendodontic pain.

International Journal of Experimental Dental Science (2021): 10.5005/jp-journals-10029-1217

\section{INTRODUCTION}

Cryotherapy alludes to bringing down or diminishing the tissue temperature for therapeutic purposes. The term cryotherapy is gotten from the Greek word cryos, signifying "cold". ${ }^{1}$ The magnitude of the adjustment in temperature and biophysical changes in the tissues rely on several factors such as the distinctions in the object's temperature and the heat or cold application, exposure duration, thermal conductivity of the tissues, and sort of thermal agents employed. The clinical ramifications of this sort of treatment in the human body cause changes in the host's nearby temperature. ${ }^{2}$

Cryotherapy has been commonly practiced in medical and other fields of dentistry for long. Recently, due to the obvious advantages and considerable positive effects, cryo-treatment is now expanding widely in the field of endodontics.

\section{Materials and Methods}

Organized electronic hunt of scientific papers promulgated was done till August 30, 2020, on the (http://www. ncbi.nlm.nih.gov/ pubmed) whole PubMed information base with no custom range and hand look for the term "Cryotherapy"; which was additionally sifted utilizing Boolean administrators (AND, OR, NOT) and blend of explicit catchphrases as following: "cryotherapy in dentistry", "cryotherapy in endodontics", "cryotreatment in endodontics", and "cryogenic treatment of nickel titanium endodontic instruments". Abstracts of all important papers were altogether investigated and at long last articles relating to the subject [cryogenic treatment (CT) in endodontics] were incorporated.

Applicable literature for "cryotherapy in endodontics" on google scholar and for extra data reference indices of papers and

\begin{abstract}
${ }^{1-4}$ Department of Conservative Dentistry and Endodontics, Saraswati Dental College and Hospital, Lucknow, Uttar Pradesh, India

${ }^{5}$ Department of Conservative Dentistry and Endodontics, Teerthanker Mahaveer Dental College and Research Centre, Moradabad, Uttar Pradesh, India

Corresponding Author: Kishan Agarwal, Department of Conservative Dentistry and Endodontics, Teerthanker Mahaveer Dental College and Research Centre, Moradabad, Uttar Pradesh, India, Phone: +91 9864513131, e-mail: kishan25021991@gmail.com
\end{abstract}

How to cite this article: Shreya, Samant PS, Srivastava V, et al. Cryotherapy: A Comprehensive Review on Physiology, Advent and Implications in Endodontics. Int J Experiment Dent Sci 2021;10(1): 36-40.

Source of support: Nil

Conflict of interest: None

review articles along with suitable peer-reviewed journals were additionally included. The inclusion standards set for this survey were: all original research articles, case reports, review articles, in vitro/in vivo examinations, and controlled clinical preliminaries on cryotherapy utilized in the field of endodontics and were distributed in the English language, related studies. Exclusion measures comprised of studies that did not meet the above inclusion models.

\section{Review Results}

The electronic pursuit yielded 253 papers from the PubMed database; in light of specifically predetermined exclusion and inclusion measures, 13 papers were distinguished as reasonable 
to the consideration standards, and the staying 240 papers were avoided. Then, a detailed study of the apparent multitude of references of these articles was done physically and electronically for extra studies on Scopus (http://www.scopus.com), Web of Science (https://www.webofknowledge.com), and Google scholar. At that point, 25 additional articles were chosen through hand search, the full content of the apparent multitude of articles recovered, and the review was finished. By pooling the extricated information from selected articles, the reviewed information was synthesized.

\section{LITERATURE \\ Physiology}

There are three fundamental physiological reactions as a result of either heat or cold application that includes; (i) vascular responses, (ii) neural responses, and (iii) an expansion or decline in tissue metabolism. ${ }^{3}$ For example, if tissue is presented to decreased temperature for longer than 15 minutes, vasoconstriction happens because of initial reflex and is trailed by cool instigated vasodilatation. ${ }^{4}$ Likewise, Van't Hoff's law expresses that cryotherapy brings about vasoconstriction and thwarts cellular metabolism by confining biochemical reactions.

This in return limits the degree of tissue damage by decreasing oxygen requirement and free radical production. ${ }^{5}$ Leakage of fluid periapically is the most common thing that occurs while doing biomechanical preparation. Vasoconstriction results in decreased permeability that is a key factor in pain reduction by limiting tissue edema and swelling. ${ }^{6}$

The absence of pain is firmly related to the nerve conduction speed of the nociceptive nerve fibers as a neurological impact. Cooling incites analgesia by easing back the speed of nerve conduction. ${ }^{7}$ Cryotherapy activates thermoreceptors that have temperature-sensitive nerve endings, in this way blocking nociception inside the spinal cord. It is well known that myelinated $A-\delta$ fibers and non-myelinated $C$-fibers are mainly responsible for dental pain conduction. Franz and Iggo have accounted that complete deactivation of myelinated $A-\delta$ fibers occurs at $7^{\circ} \mathrm{C}$ whereas non-myelinated $\mathrm{C}$-fibers get deactivated at about $3^{\circ} \mathrm{C} .{ }^{8}$

Concerning the impact of cryotherapy on tissue metabolism, oxygen demand increases following injury, ensuing hypoxia, and necrosis of the tissues. As explained earlier, cryotherapy diminishes tissue bloodstream and metabolism to almost half, thusly hinders the pace of biochemical responses, restricting the free radical formation in tissues. It further decreases the pace of oxygen utilization; and forestalls added tissue injury. ${ }^{5}$

Along these lines, the agony diminishing effect coming about in light of cryotherapy is dominatingly made by a blend of vasoconstriction, a diminished arrival of chemical mediators of pain, and more slow conduction of neural pain signals.

\section{Implications of CRYotreatment in ENDODONTICS}

\section{Reduction in Postendodontic Pain}

Endodontic treatment is mainly intended to result in the elimination of root canal infection using an appropriate biomechanical cleaning and shaping process followed by solid obturation to accomplish a hermetic seal, in this way to give a helpful situation to peri-radicular healing. However, many times, pain or flare-ups are experienced by the patients even after taking the utmost care while performing root canal treatment. ${ }^{9}$

Usually, symptomatic apical periodontitis is the exemplary presentation of postendodontic pain (PEP). The physiology behind it is alike the quintessential acute inflammatory reaction in several other tissues of the body. Following injury, vasodilation occurs that results in increased permeability, subsequently transmigration of leukocytes (neutrophils and macrophages) takes place. These inflammatory events cause damage at tissue level and out-turn in pain and swelling. ${ }^{10}$

The rate of PEP was accounted for to go from 3 to $58 \% .^{11}$

In dentistry, though the cryo-treatment is found to be effective in many intraoral surgical procedures, its exact mechanism needs some strong evidences to support the explained literature. Notwithstanding, lately, scarcely any investigations have endeavored as well as revealed the intracanal utilization of cryotherapy to diminish postoperative pain, in endodontics.

For example, in the field of endodontics, cryotherapy was first introduced by Vera et al., ${ }^{12}$ first introduced the use of cryotherapy in endodontics and validated this new procedure to decrease and keep up outside root surface temperature for at any rate 4 minutes. In his in vitro study, he observed a decline in the external temperature of the root surface by $>10^{\circ} \mathrm{C}$ and was kept up for 4 minutes when cold saline $\left(2.5^{\circ} \mathrm{C}\right)$ was utilized as a last irrigant. An anti-inflammatory impact in the periradicular tissues was thought to be initiated due to this procedure.

Keskin et al. ${ }^{13}$ conducted the first clinical trial in patients with irreversible pulpitis by assessing the impact of $2.5^{\circ} \mathrm{C}$ cold saline irrigation on PEP when used as a final irrigant. To negate additional effect of negative apical pressure on reducing postoperative pain, a side-vented, positive-pressure needle was used. Protocols were the same as that of Vera et al. ${ }^{12}$ They reported a noteworthy pain decrease levels when contrasted with the control group. ${ }^{13}$ Al-Nahlawi et al. ${ }^{14}$ conducted a clinical study on the vital teeth, to assess the impacts of intracanal cryotherapy after a single visit endodontic treatment along with negative irrigation technique and found a reduction in PEP significantly.

A randomized controlled trial among 40 patients having irreversible pulpitis with apical periodontitis and not having apical periodontitis, was conducted by Bazaid et al. ${ }^{15}$ They compared the impact of intracanal cryotherapy in decreasing postoperative pain and found it effective in cases of irreversible pulpitis having apical periodontitis but not in cases without apical periodontitis. The result found here is analogous to the investigation by Jain et al., ${ }^{16}$ who found intracanal cryotherapy successful in diminishing postoperative pain in patient having irreversible pulpitis along with apical periodontitis at 6,24 , and 48 hours interval. Final irrigation in their study was carried out with either $2.5^{\circ} \mathrm{C}$ cold saline or saline at room temperature. Patients were given a questionnaire to record their postoperative pain at 6, 24, and 48 hours.

Sadaf ${ }^{17}$ led a randomized clinical preliminary to survey the impacts of extraoral, intraoral, and intracanal cryotherapy on the PEP in patients going through root canal treatment, for symptomatic apical periodontitis. On days 1, 3, 5, and 7, the primary result for postoperative pain was given an account utilizing a 100-mm VAS score. Patients reported more prominent postoperative pain decrease after getting cryotherapy (intracanal, intraoral, and extraoral) treatment than those in the control group at all focuses. 
Alharthi et al. ${ }^{18}$ evaluated the impact of normal saline on postoperative pain when it was used as a last irrigant at cold and room temperature in single-visit endodontic treatment. Only the asymptomatic patients were included in this study. Normal saline at room temperature was found to be comparable with cryotherapy in terms of postoperative pain reduction in asymptomatic patients.

Vieyra et al. ${ }^{19}$ directed a clinical preliminary to survey whether a controlled water system with three diverse water system regimens (17\% EDTA and $10 \mathrm{~mL}$ of cold saline arrangement) and distinctive temperature $\left(4^{\circ} \mathrm{C}, 2.5^{\circ} \mathrm{C}\right.$, and room temperature) would bring about decrease of postendodontic torment following single visit root canal treatment. It was presumed that cryotherapy decreased the event of PEP. So, it could aid in chemomechanical preparation procedures and furthermore the drug prerequisite in patients with vital pulp could be limited.

A prospective, multi-centered, randomized clinical trial was conducted by Vera et al., ${ }^{20}$ in patients having pulp necrosis and symptomatic apical periodontitis, to assess whenever controlled cold saline irrigation could bring about less frequency and power of PEP and thought that it was compelling.

Al-Abdullah et al., ${ }^{21}$ in their recent study, evaluated the role of cryotherapy in postoperative pain after using two different preparation techniques in vital single root with single canal teeth. There were no PEP values in all monitoring periods for groups with cold saline. There was a significant difference $(p<0.05)$ in all study periods except after 1 week among the groups of ProTaper Universal preparation with cold saline and without cold saline. The intracanal cryotherapy eliminated PEP clinically which could be explained in a way that possibly the reduced temperature of the periapical area had initiated a local anti-inflammatory effect by reducing edema, which is in agreement with the Vera et al. ${ }^{12}$

\section{Effect of Cryogenic Treatment on Nickel-Titanium Endodontic Instrument}

The extraordinary properties of shape memory, superelasticity, superb biocompatibility, and elevated corrosion resistance is shown by the nickel-titanium (NiTi) alloys that aid in better biomechanical preparation. In contrast to stainless steel, $\mathrm{NiTi}$ shows greater adaptability, flexibility, and torsional fatigue resistance. Nonetheless, the machining process may prompt surface imperfections inside the cutting surfaces and a relatively reduced cutting efficiency (CE), ${ }^{22}$ due to its pseudoelastic property. They additionally show lower microhardness than hardened steel instruments. ${ }^{23,24}$ These all factors together diminishes the CE of NiTi instruments.

To ameliorate the CE and wear resistance of nickel-titanium instruments, different surface treatment procedures have been attempted. ${ }^{25}$ Interestingly, the CT influences the whole cross-region of the metal as opposed to simply the surface. ${ }^{26}$

\section{The Cryogenic Process}

Cryogenic treatment is a two-stage cycle that includes submerging the metal in a super-cooled bath that contains fluid nitrogen at $-196^{\circ} \mathrm{C}$ or $-320^{\circ} \mathrm{F}$ and permitting it to gradually cold out to arrive at room temperature. ${ }^{27,28}$ In light of the treatment temperature, CT falls into shallow and deep categories. ${ }^{29}$ Conventional below zero treatments have been being used at roughly $-80^{\circ} \mathrm{C}$ (shallow). However, the device life develops at lower temperatures (deep) actuated by liquid nitrogen at -185 and $-196^{\circ} \mathrm{C} .{ }^{30}$ The cycle is marked as wet as the material is submerged in aqueous nitrogen, while in a dry cycle the material is simply held at a situation over the degree of nitrogen in liquid state. ${ }^{26}$

\section{Microhardness}

The cold treatment had been implemented on metals for a long to improve the surface hardness and warm steadiness during the manufacturing process. ${ }^{30}$ The $C T$ had been appeared to have more gainful impacts than the customary cold treatment utilizing higher temperature, ${ }^{31}$ which incorporate expanding cutting productivity just as the general quality of the metal. ${ }^{30,32}$ Kim et al. ${ }^{27}$ investigated the effects of CT on NiTi endodontic instruments and found that the degree of microhardness increased after the CT. Increased microhardness could be the result strain inside the nuclear grid because of the testimony of nitrogen inside the interstitial spaces.

\section{Cutting Efficiency}

Vinothkumar et al. $^{26}$ investigated the impact of CT on NiTi endodontic instruments regarding CE and wear resistance by using ten rotary $\mathrm{NiTi}$ instruments, which were exposed to profound dry CT at $185^{\circ} \mathrm{C}$. They concluded that the deep dry CT enhanced the cutting proficiency of rotary $\mathrm{NiTi}$ endodontic instruments (ProFile) significantly $(p<0.05)$ but the effect on wear resistance was insignificant. Also, the fewer number imperfections could be brought about by an enhancement in microhardness after $\mathrm{CT}$, which was clinically noteworthy.

\section{Cyclic Fatigue}

Sabet et al. ${ }^{33}$ assessed the impact of CT on the cyclic fatigue resistance of rotary nickel-titanium instruments (Hyflex) and confirmed that although CT could bring about a reduction in the cycles of the fracture in the group receiving the process, it had a limited impact. The aftereffects of the current study suggested that the slight decrease in the mean of cycles ending to the fracture could probably result from either the proprietary manufacturing process (with exclusive warming and cooling measures) or from the difference in weight of nickel in Hyflex instruments, both of which might be inconsistent with $\mathrm{CT}$. The negative findings could be associated with the Hyflex instruments with special thermal processes, which are absent in the traditional instruments.

Also, George et al., ${ }^{34}$ in an in vitro study, demonstrated a noteworthy increment in the cyclic fatigue resistance of deep dry cryo-treated NiTi files over untreated ones.

\section{Fracture Resistance}

George et al. ${ }^{34}$ indicated that the fracture time was significantly more in three different rotary files (Hero Shaper, $\mathrm{RaCe}$, and K3) after deep dry CT and concluded that the increase in the level of hardness could be attributed to the alloy completely transforming from the austenitic to martensitic phase. Such a change in phases normally occurs at $-195^{\circ} \mathrm{C}$ and could bring about a reduction in the level of internal stress within the alloy as a result of plastic deformation.

\section{Intracanal Cryotherapy Effect on Fracture Resistance of Tooth}

Besides its encouraging role in pain control policy with negligible concomitant, setting up whether intracanal cryotherapy has any impact on the mechanical conduct of teeth is likewise significant.

Keskin et al. ${ }^{35}$ conducted a study on endodontically treated teeth and assessed the impact of intracanal cryotherapy on their 
fracture resistance. They concluded that the vertical fracture resistance diminished after the application of intracanal cryotherapy as a final irrigant when contrasted with the benchmark group. The utilization of cold water from within the pulp space may bring about a more articulated thermal stress in the dentin substance as a result of the absence of enamel structure and the distinctive tubular microstructure of the dentin closer to the pulp space.

\section{Periradicular Surgery}

Neighborhood bloodstream is hindered by the postsurgical cold application that neutralizes the bounce back marvel, which follows the utilization of vasoconstrictor-containing local anesthetics. Along these lines, decreasing the temperature of the operative site by application of cold has become the suggested convention in postsurgical steady treatment. ${ }^{6}$

\section{Vital Pulp Therapy in Conjunction with Cryotherapy}

Recently, cryotherapy was used in a case of vital pulp therapy by Bahcall et al., ${ }^{36}$ for hemorrhage control from the inflamed pulp during direct pulp capping.

Shaved sterile water ice $\left(0^{\circ} \mathrm{C}\right)$ was placed over the direct or the roundabout introduction of the pulpal tissue alongside the whole tooth for 1 minute, the liquified ice was eliminated with suction of high speed. After the removal, the exposed pulp was irrigated with $17 \%$ EDTA and restored with Bioceramic material. It was noticed that teeth stayed asymptomatic, vital, and practical over the subsequent period of 12 to a year and a half. To determine the long-term prognosis of cryotherapy in vital pulp therapy, more clinical studies were recommended.

\section{Effect of Cryotherapy on Inferior Alveolar Nerve Block}

Recently, Topcuoglu et al. ${ }^{37}$ evaluated the impact of preoperative intraoral cryotherapy application on the success rate of inferior alveolar nerve blocks (IANBs) in a randomized clinical trial. The trial included the patients having symptomatic irreversible pulpitis (SIP). They favored this procedure as a basic and modest assistant application to enhance the effectiveness of IANBs in patients with SIP. The expanded viability of the IANB in the cryotherapy group could be clarified with the adequacy of cryotherapy in inciting a local anesthetic effect by bringing down the activation threshold of nociceptors and the conduction speed of pain signals.

\section{Antimicrobial Efficacy of Cryotreatment against Enterococcus faecalis}

Mandras et al. tested the potential microbicidal properties of cryotherapic treatment along with $5 \% \mathrm{NaOCl}$ against Ent. faecalis. Cryotreatment was done utilizing a dental instrument outfitted with a duct and associated with a cryogenic liquid source (liquid nitrogen), with a cooling needle getting the cryogenic fluid.

The utilization of cryo-instrumentation along with $\mathrm{NaOCl}$ irrigation fundamentally decreased the quantity of Ent. faecalis $(p<0.01)$ in the root channel. So, it appeared to greatly affect the decrease in microscopic organisms contrasted with a standard $\mathrm{NaOCl} .^{38}$

\section{Conclusion}

As of late by demonstrating great promising outcomes with the utilization of cryotherapy, it has demonstrated to have a decent possibility for its utilization as a therapeutic boon in endodontics.
The effect of CT on the mechanical properties of recent generations of nickel-titanium rotary instruments is also praiseworthy. In any case, more exploration studies ought to be directed soon to research the potential advantages of this method.

\section{Clinical Significance}

Cryotherapy is a cost-effective treatment that can be advantageous in numerous clinical circumstances to provide painless and safer endodontic treatment.

\section{Acknowledgment}

I would like to acknowledge my work to the entire Department of Conservative Dentistry and Endodontics, Saraswati Dental College and Hospital, Lucknow, Uttar Pradesh, India.

\section{References}

1. Belitsky RB, Odam SJ, Hubley-Kozey C. Evaluation of the effectiveness of wet ice, dry ice, and cryogenic packs in reducing skin temperature. Phys Ther 1987;67(7):1080-1084. DOI: 10.1093/ptj/67.7.1080.

2. Hubbard TJ, Denegar CR. Does cryotherapy improve outcomes with soft tissue injury? J Athl Train 2004;39(3):278-279.

3. Balasubramanian SK, Vinayachandran D. "Cryotherapy" - a panacea for post-operative pain following endodontic treatment. Acta Sci Dent Sci 2017;1(1):1-3. DOI: 10.31080/ASMI.2018.01.0001.

4. Salmassy DA, Pogrel MA. Liquid nitrogen cryosurgery and immediate bone grafting in the management of aggressive primary jaw lesions. J Oral Maxillofac Surg 1995;53(7):784-790. DOI: 10.1016/02782391(95)90333-x.

5. Nadler SF, Weingand K, Kruse RJ. The physiologic basis and clinical applications of cryotherapy and thermotherapy for the pain practitioner. Pain Physician 2004;7(3):395-399. DOI: 10.36076/ ppj.2004/7/395.

6. Fayyad DM, Abdelsalam N, Hashem N. Cryotherapy: a new paradigm of treatment in endodontics. J Endod 2020;46(7):936-942. DOI: 10.1016/j.joen.2020.03.019.

7. Algafly AA, George KP. The effect of cryotherapy on nerve conduction velocity, pain threshold and pain tolerance. Br J Sports Med 2007 Jun;41(6):365-369. DOI: 10.1136/bjsm.2006.031237.

8. Franz DN, Iggo A. Conduction failure in myelinated and nonmyelinated axons at low temperatures. J Physiol 1968;199(2):319-345. DOI: 10.1113/jphysiol.1968.sp008656.

9. Rosenberg PA. Clinical strategies for managing endodontic pain. Endodontic Topics 2002;3(1):78-92. DOI: 10.1034/j.16011546.2002.30108.x.

10. Blicher B, Pryles R, Lin J. Endodontics review: a study guide. Hanover Park, IL: Quintessence Publishing Co Inc; 2016. pp. 45-66.

11. Sathorn C, Parashos P, Messer H. The prevalence of postoperative pain and flare-up in single- and multiple-visit endodontic treatment: a systematic review. Int Endod J 2008;41(2):91-99. DOI: 10.1111/j.13652591.2007.01316.x.

12. Vera J, Ochoa-Rivera J, Vazquez-Carcaño M, et al. Effect of intracanal cryotherapy on reducing root surface temperature. J Endod 2015;41(11):1884-1887. DOI: 10.1016/j.joen.2015.08.009.

13. Keskin C, Ozdemir O, Uzun I, et al. Effect of intracanal cryotherapy on pain after single-visit root canal treatment. Aust Endod J 2017;43(2):83-88. DOI: 10.1111/aej.12175.

14. Al-Nahlawi T, Hatab TA, Alrazak MA, et al. Effect of intracanal cryotherapy and negative irrigation technique on postendodontic pain. J Contemp Dent Pract 2016;17(12):990-996. DOI: 10.5005/ jp-journals-10024-1969.

15. Bazaid DS, Kenawi LM. The effect of intracanal cryotherapy in reducing postoperative pain in patients with irreversible pulpitis: a randomized control trial. Int J Health Sci 2018;8:83-88. 
16. Jain A, Davis $D$, Bahuguna $R$, et al. Role of cryotherapy in reducing postoperative pain in patients with irreversible pulpitis. an in-vivo study. Int J Den Med Sci 2018;2:43-49.

17. Sadaf D. Limited quality evidence suggests that application of cryotherapy may be helpful in reducing postoperative pain in root canal therapy in patients with symptomatic apical periodontitis. J Evid Based Dent Pract 2019;19(2):195-197. DOI: 10.1016/j. jebdp.2019.05.005.

18. Alharthi AA, Aljoudi MH, Almaliki MN, et al. Effect of intra-canal cryotherapy on post-endodontic pain in single-visit RCT: a randomized controlled trial. Saudi Dent J 2019;31(3):330-335. DOI: 10.1016/j.sdentj.2019.03.004

19. Vieyra JP, Enriquez FJJ, Acosta FO, et al. Reduction of postendodontic pain after one-visit root canal treatment using three irrigating regimens with different temperature. Niger J Clin Pract 2019;22(1):3440. DOI: 10.4103/njcp.njcp_349_18.

20. Vera J, Ochoa J, Romero M, et al. Intracanal cryotherapy reduces postoperative pain in teeth with symptomatic apical periodontitis: a randomized multicenter clinical trial. J Endod 2018;44(1):4-8. DOI: 10.1016/j.joen.2017.08.038.

21. Al-Abdullah A, Abdullah A, Al-Marrawi K. Comparative study to investigate the effect of cryotherapy on post-operative pain using two different preparation techniques (In vivo study). Int J Appl Dent Sci 2020;6(3):163-168.

22. Thompson SA. An overview of nickel-titanium alloys used in dentistry. Int Endod J 2000;33(4):297-310. DOI: 10.1046/j.13652591.2000.00339.x.

23. Brockhurst PJ, Denholm I. Hardness and strength of endodontic files and reamers. J Endod 1996;22(2):68-70. DOI: 10.1016/S0099. 2399(96)80274-3.

24. Brockhurst $\mathrm{P}, \mathrm{Hsu}$ E. Hardness and strength of endodontic instruments made from NiTi alloy. Aust Endod J 1998;24(3):115-119. DOI: 10.1111/ j.1747-4477.1998.tb00034.x.

25. Lee DH, Park B, Saxena A, et al. Enhanced surface hardness by boron implantation in nitinol alloy. J Endod 1996;22(10):543-546. DOI: 10.1016/S0099-2399(96)80015-X.

26. Vinothkumar TS, Miglani R, Lakshminarayananan L. Influence of deep dry cryogenic treatment on cutting efficiency and wear resistance of nickel-titanium rotary endodontic instruments. J Endod 2007;33(11):1355-1358. DOI: 10.1016/j.joen.2007.07.017.
27. Kim JW, Griggs JA, Regan JD, et al. Effect of cryogenic treatment on nickel-titanium endodontic instruments. Int Endod J 2005;38(6):364371. DOI: 10.1111/j.1365-2591.2005.00945.x.

28. Bensely A, Prabhakaran A, Mohan Lal D, et al. Enhancing the wear resistance of case carburized steel (En 353) by cryogenic treatment. Cryogenics 2005;45(12):747-754. DOI: 10.1016/j. cryogenics.2005.10.004.

29. Singh PJ, Guha B, Achar DRG. Fatigue life improvement of AISI 304L cruciform welded joints by cryogenic treatment. Eng Fail Anal 2003;10(1):1-12. DOI: 10.1016/S1350-6307(02)00033-X.

30. Molinari A, Pellizzari M, Gialanella S, et al. Effect of cryogenic treatment on the mechanical properties of tool steels. J Mater Process Technol 2001;118(1-3):350-355. DOI: 10.1016/S0924-0136(01) 00973-6.

31. Moore K, Collins DN. Cryogenic treatment on three heat treated tool steels. Eng Mater 1993;86:47-54. DOI: 10.4028/www.scientific.net/ KEM.86-87.47.

32. Huang JY, Ahu YT, Liao XZ. Microstructure of cryogenic treated $M 2$ tool steel. Mater Sci Eng A339 2003(1-2):241-244. DOI: 10.1016/S09215093(02)00165-X.

33. Sabet Y, Shahsiah S, Yazdizadeh M, et al. Effect of deep cryogenic treatment on cyclic fatigue resistance of controlled memory wire nickel-titanium rotary instruments. Dent Res J (Isfahan) 2020;17(4):300-305. DOI: 10.4103/1735-3327.292069.

34. George GK, Sanjeev K, Sekar M. An in vitro evaluation of the effect of deep dry cryotreatment on the cutting efficiency of three rotary nickel titanium instruments. J Conserv Dent 2011;14(2):169-172. DOI: 10.4103/0972-0707.82627.

35. Keskin C, Sariyilmaz E, Keleş A, et al. Effect of intracanal cryotherapy on the fracture resistance of endodontically treated teeth. Acta Odontol Scand 2019;77(2):164-167. DOI: 10.1080/00016357.2018.1549748.

36. Bahcall J, Johnson B, Xie Q, et al. Introduction to vital pulp cryotherapy. Endod Pract US 2019;1:14.

37. Topçuoğlu HS, Arslan H, Topçuoğlu G, et al. The effect of cryotherapy application on the success rate of inferior alveolar nerve block in patients with symptomatic irreversible pulpitis. J Endod 2019;45(8):965-969. DOI: 10.1016/j.joen.2019.05.001.

38. Mandras N, Allizond V, Bianco A, et al. Antimicrobial efficacy of cryotreatment against enterococcus faecalis in root canals. Lett Appl Microbiol 2013;56(2):95-98. DOI: 10.1111/lam.12017. 